
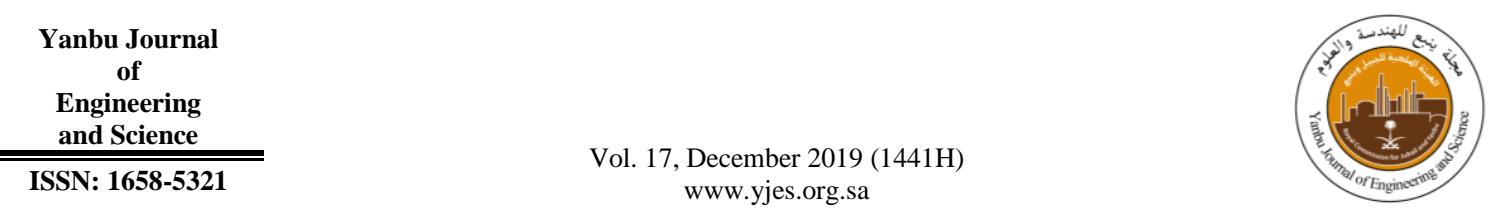

\title{
GRASSHOPPER OPTIMIZATION APPROACH FOR POWER SYSTEM STABILIZERS PATTERN
}

\author{
E. S. Ali ${ }^{1,2}$ and S. M. Abd Elazim ${ }^{1,3}$ \\ ${ }^{I}$ Electric Power and Machine Department, Faculty of Engineering, Zagazig University, Egypt. \\ ${ }^{2}$ Currently, Faculty of Computer Science Department, Computer Science and Information Systems, Jazan University, KSA. \\ ${ }^{3}$ Currently, Faculty of Computer Science Department, Computer Science and Information \\ E-mail: ehabsalimalisalama@yahoo.com
}

\begin{abstract}
In this cover, a new meta-heuristic approach called Grasshopper Optimization Approach (GOA) for Power System Stabilizer (PSS) pattern problem is inspected. The parameters of PSSs are perfected by GOA to belittle the time domain objective function. The showing of the organized GOA based PSSs (GOAPSS) has been competed with Differential Evolution (DE) based PSSs (DEPSS) and the Particle Swarm Optimization (PSO) based PSSs (PSOPSS) under varied burden events. The results of the decided GOAPSS are affirmed via damping ratio, eigenvalues, performance indices, and time domain analysis. In addition, the strength of the GOA in earning generous damping characteristics is belayed.
\end{abstract}

Keywords: PSS; Damping Oscillations; Grasshopper Optimization Approach; Differential Evolution; Particle Swarm Optimization.

\section{INTRODUCTION}

System stability is one of the neoteric critical issues in the dissection of power system [1]. One of the obligatory occurrences of this is a linked power system. The heavily filled long tie-lines could show cause for a diversity of stability matters [2]. This leads to the tendency of the primary investigators towards styling of a compatible Power System Stabilizer (PSS). Latterly, a lot of treatises is depend on an area namely "Heuristics from Nature" in that the identification of social or nature systems are being applied [3]. These ways when exercised in research folk can prove their might of finding optimal solutions of multi-model, gleaner objective and nondifferentiable functions. Distinct new approaches have been consumed for styling a PSS as Differential Evolution (DE) [4],
Particle Swarm Optimization (PSO) [5], Bacterial Swarm Optimization (BSO) [6,7], Harmony Search Approach (HSA) [8,9], Bacterial Foraging (BF) [10,11], Bat Approach (BA) [12,13], Water Cycle Approach (WCA) [14], Backtracking Search Approach (BSA) [15-16], Grey Wolf Approach (GWA) [17], Whale Optimization Approach (WOA) [18], Cuckoo Search Approach (CSA) [19,20], Flower Pollination Approach (FPA) [21], Genetic Approach (GA) [22], Kidney-Inspired Approach (KIA) [23], etc. All of these approaches are depend on Artificial Intelligence (AI). A new nature-inspired mechanism filled with social actions of grasshoppers is inserted by Mirjalili. The mechanism is termed as Grasshopper Optimization Approach (GOA) [24]. It has been ordinarily carried out these days due to 
its plainness, inspiration by ease, and obviating the high local optimum value as gradient-free approach. Thus, influence of realization the proposed approach to address real-life issues is estimated. The solutions must be perfected in nature-inspired approaches pending the end criterion is met. Alongside this, the optimization approach parted in two routes named exploration and exploitation. Exploration connects to the algorithm's penchant to have randomized demeanor to mutate the solutions. Considerable variations in solutions lead to supplementary search space exploration and thence discovery of its auspicious area. However, as an approach tends to exploit, solutions ordinarily encounter smaller-scale modulations and tend to frisk locally. A compatible exploration and exploitation balance can make the search for the global optimum of a particular optimization problem. It is conspicuous from [24] that the GOA approach gives afflicted results as compared with sundry optimization techniques. Former works visibly reflect the growing heed of the researchers in styling PSS when it comes to stability betterment. Furthermore, the GOA approach has not been consumed.

\section{PROBLEM FORMATION}

\subsection{Power System Paradigm}

Ordinarily, a power system can be instituted by a collection of nonlinear differential equations as:

$$
\dot{X}=f(\mathrm{X}, \mathrm{U})
$$

Where $\mathrm{X}$ and $\mathrm{U}$ are the transmitter of the state quantities and of sign quantities. In this cover, $\mathrm{X}=\left[\delta, \omega, \mathrm{E}_{q}^{\prime}, E_{f d}, V_{f}\right]^{T}$ and $\mathrm{U}$ is the sign of PSSs. $E_{q}^{\prime}, E_{f d}$ and $V_{f}$ are the inside, the field, and rousing emf respectively. Likewise, $\omega$ and $\delta$ are the speed and rotor angle, respectively.
The state equation of a power system can be constituted as:

$$
\dot{X}=\mathrm{AX}+\mathrm{BU}
$$

\subsection{PSS STRUCTURE}

Due to the quality of online tuning, power scheme companies promote the construction of conventional PSS (CPSS). The congruent action of the CPSS parameters results in acceptable show during the system disturbances.

The CPSS can be shapely as:

$$
\Delta \mathrm{U}_{\mathrm{i}}=\mathrm{K}_{\mathrm{i}} \frac{\mathrm{ST}_{\mathrm{W}}}{\left(1+\mathrm{ST}_{\mathrm{W}}\right)}\left[\frac{\left(1+\mathrm{ST}_{1 \mathrm{i}}\right)}{\left(1+\mathrm{ST}_{2 \mathrm{i}}\right.} \frac{\left(1+\mathrm{ST}_{3 \mathrm{i}}\right)}{\left(1+\mathrm{ST}_{4 \mathrm{i}}\right)}\right] \Delta \omega_{\mathrm{i}}
$$

Figure 1 imparts the block draw of CPSS and irritation system. The pattern of CPSS holds a limiter, an earn, a washout filter and a dynamic compensator. To refrain the delay between the electric torque and the excitation, two lead-lag circuits are countenanced $[1,2]$. In this press, the time constants $T_{1 i}$, and $T_{3 i}$, and the earn $K_{i}$ are perfected by GOA to decoct a time domain objective function.

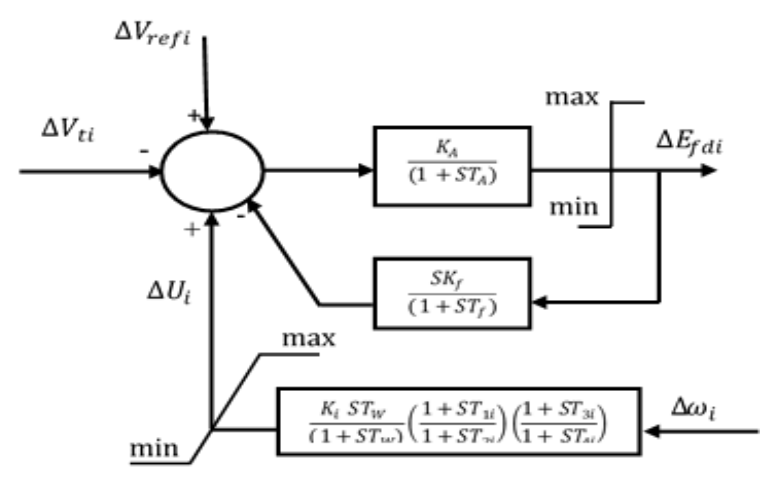

Fig. 1. Block draw of $i^{\text {th }}$ CPSS with excitation system.

\subsection{TeST System}

A multimachine system that exists of nine buses and three generators is excogitated here. The loading events and system data are protruded in $[2,25]$. 


\section{GRASSHOPPER OPTIMIZATION APPROACH}

GOA is an intelligence approach acquainted by Mirjalili [24]. It is a population-based approach, which simulates grasshopperswarming conduct. It is an insect plague since it has withering mark on corps. Its live has two platforms, nymph and adulthood. The insects possess no wings for nymph platform so they shift inactively but after growing up, they transmute adults with wings that grant them to relocation rattling nonviolence concealment a large-scale region. Grasshopper swarming might be contemplated as the maximal one among all individual as it is a situation for farmers. In swarming operation, there is a larval period, which defined by decelerate shitting with lesser grasshopper intervals but for adults eternal -rang and precipitous shitting. In food seeking operation, grasshopper espouses two strategies, exploration and exploitation. Each grasshopper transposes a solution, the next position $\mathrm{X}_{\mathrm{j}}$ is persuaded by the gregarious interaction between grasshopper and the else one $S_{j}$, wind advection $A_{j}$ and gravity force $G_{j}$ as evinced in the equation (4):

$$
X_{j}=S_{j}+G_{j}+A_{j}
$$

Social interaction can be enumerated by equations $(5,6)$

$$
\begin{aligned}
& S_{j}=\sum_{k=1}^{N} s\left(d_{i k}\right) \cdot \hat{d}_{i k} \quad k \neq i \\
& d_{i k}=\left|X_{k}-X_{i}\right| \text { and } \quad \hat{d}_{i k}=\frac{X_{k}-X_{i}}{d_{i k}}
\end{aligned}
$$

Where $d_{i k}$ is the interval from grasshopper $\mathrm{k}$ to grasshopper i, N is no. of grasshoppers, $\mathrm{s}$ and $i$ is the strength of repulsion and attraction forces between grasshoppers. Since repulsion force seems when interval between grasshoppers between zero and 2.079 units, while at an interval of 2.079 neither attraction nor repulsion force, as it is a soothing zone.
Attraction force increments at an interval higher than 2.079 till reach 4 then it will be diminished and after 10 , there will be no forces. Form the preceding; the distance should be from 1 to 4 and $\mathrm{s}$ can be enumerated by equation (7):

$$
s(r)=a e^{\frac{r}{\mathbb{l}}}-e^{-r}
$$

Where $l$ is the attractive size scale and a is the intensity of attraction. Gravity force can be enumerated by equation (8):

$$
G_{j}=g \hat{e}_{g}
$$

Where $g$ is a gravitational invariable and $\hat{e}_{g}$ is the center of earth unit vector. Wind advection force $A_{j}$ can be enumerated by equation (9):

$$
A_{j}=u \hat{e}_{w}
$$

Where $u$ is a drift invariable and $\hat{e}_{u}$ is the wind direction unit vector Equation (4) will be enumerated as following:

$$
\begin{gathered}
X_{j}=\sum_{k=1}^{N}\left(a e^{r}-e^{-r}\right)\left(\left|X_{k}-X_{\mathrm{i}}\right|\right) \cdot \frac{X_{k}-X_{\mathrm{i}}}{d_{i k}} \\
-g \hat{\theta}_{g}+u \hat{e}_{W W} \quad k \neq i
\end{gathered}
$$

To desist soothing area and global optimum, the grasshopper place will be

$X_{j}^{d}=c\left[\sum_{k=1}^{N} c\left(\frac{u b_{d}-l b_{d}}{2}\right) s\left(\left|X_{k}^{d}-X_{i}^{d}\right|\right) \cdot \frac{X_{k}-X_{i}}{d_{i k}}\right]+\hat{T}_{d}$

Where $u b_{d}$ and $l b_{d}$ state the upper and lower borders respectively in $\mathrm{D}^{\text {th }}$ dimension, $\widehat{T}_{d}$ is the spot value anticipating wind direction tends to spot and $\mathrm{c}$ is diminishing constant to derogate all zones declining gravity.

$$
c=c \max -l \frac{c \max -c \min }{L}
$$

$l$ is the prevailing iteration, $\operatorname{cmin}=10^{-5}$, $\operatorname{cmax}=1$ and $\mathrm{L}$ is the greatest number of iterations. Figure 2 shows the flow chart of GOA. In addition, other recent applications for GOA can be found in [26, 27, 28 and 29]. 


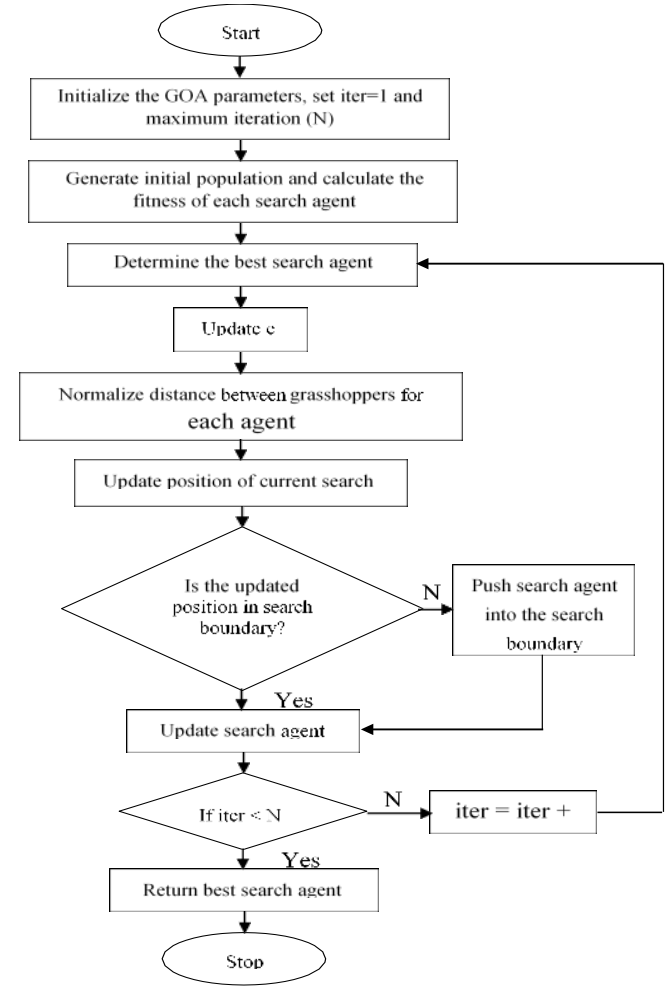

Fig. 2. GOA Flow chart

\section{OBJECTIVE FUNCTION}

An (ITAE) Integral Time Absolute Error of the speed divagation of generator is contemplated as the planned objective function. It can be engrossed as:

$$
J=\int_{0}^{t} t\left\{\left|\Delta \omega_{12}\right|+\left|\Delta \omega_{23}\right|+\left|\Delta \omega_{13}\right|\right\} d t
$$

The lower and upper bounds of the stabilizer amount are [1-50]. Further, these bounds are [0.06-1] for $T_{1 i}$ and $T_{3 i}$. Other constants $T_{2 i}$ and $T_{4 i}$ are concentrated at 0.05 second. GOA seeks for the best quantities of PSSs to heighten the damping action and decoct the settling time and overshoots of the system response.

\section{RESULTS AND ANALYSIS}

The damping ratios and eigenvalues of mechanical modes are granted in Table 1 for three varied loading conditions and diverse approaches. It is provable that, the damping factors corresponding to GOAPSS are ameliorated to be ( $\sigma=-1.12,-1.19,-1.32)$ and the eigenvalues have been displaced to the left of S plane. Moreover, the damping ratios cognate to GOAPSS are higher than other approaches. Thus, GOAPSS cogitates better damping execution compared with PSOPSS and DEPSS. In addition, the constants of each controller obtaining by GOA, PSO and DE are appeared in Table 2.

TABLE 1: MECHANICAL MODES AND DAMPING RATIOS FOR DIVERSE LOADING EVENTS AND APPROACHES.

\begin{tabular}{|c|c|c|c|}
\hline \multirow{4}{*}{$\begin{array}{c}\text { Light } \\
\text { load }\end{array}$} & $-2.43 \pm 4.01 \mathrm{j}, .51$ & $-3.75 \pm 6.23 \mathrm{j}, .51$ & $-6.3 \pm 6.34 \mathrm{j}, .7$ \\
\cline { 2 - 4 } & $-22 \pm .67 \mathrm{j}, .31$ & $-1.06 \pm .66 \mathrm{j}, .85$ & $-1.12 \pm .64 \mathrm{j}, .87$ \\
\hline \multirow{4}{*}{$\begin{array}{c}\text { Natural } \\
\text { load }\end{array}$} & $-2.41 \pm 4.32 \mathrm{j}, .48$ & $-4.29 \pm 7 \mathrm{j}, .52$ & $-6.9 \pm 6.88 \mathrm{j}, .71$ \\
\cline { 2 - 4 } & $-.36 \pm .72 \mathrm{j}, .37$ & $-3.65 \pm 5.94 \mathrm{j}, .52$ & $-3.33 \pm 5.12 \mathrm{j}, .54$ \\
\cline { 2 - 4 } & $-3.64 \pm 8.17 \mathrm{j}, .41$ & $-4.21 \pm 8.02 \mathrm{j}, .46$ & $-3.37 \pm 5.24 \mathrm{j}, .54$ \\
\hline \multirow{3}{*}{$\begin{array}{c}\text { Heavy } \\
\text { load }\end{array}$} & $-1.99 \pm 4.31 \mathrm{j}, .42$ & $-3.52 \pm 6.7 \mathrm{j}, .47$ & $-7.99 \pm 5.34 \mathrm{j}, .83$ \\
\cline { 2 - 4 } & $-.35 \pm .89 \mathrm{j}, .36$ & $-1.19 \pm .71 \mathrm{j}, .86$ & $-1.32 \pm .72 \mathrm{j}, .88$ \\
\cline { 2 - 5 } & $-3.8 \pm 8.9 \mathrm{j}, .39$ & $-3.06 \pm 5.15 \mathrm{j}, .51$ & $-4.65 \pm 7.29 \mathrm{j}, .54$ \\
\hline
\end{tabular}

TABLE 2: CONSTANTS OF CONTROLLERS FOR DIVERSE APPROACHES.

\begin{tabular}{|c|c|c|c|}
\hline & GOA & DE & PSO \\
\hline PSS $_{1}$ & $\mathrm{~K}=42.128$ & $\mathrm{~K}=27.4566$ & $\mathrm{~K}=17.4736$ \\
& $\mathrm{~T}_{1}=0.5436$ & $\mathrm{~T}_{1}=0.5264$ & $\mathrm{~T}_{1}=0.4224$ \\
& $\mathrm{~T}_{3}=0.428$ & $\mathrm{~T}_{3}=0.7578$ & $\mathrm{~T}_{3}=0.7853$ \\
\hline PSS $_{2}$ & $\mathrm{~K}=9.4211$ & $\mathrm{~K}=7.9983$ & $\mathrm{~K}=6.3649$ \\
& $\mathrm{~T}_{1}=0.4723$ & $\mathrm{~T}_{1}=0.3108$ & $\mathrm{~T}_{1}=0.5542$ \\
& $\mathrm{~T}_{3}=0.1643$ & $\mathrm{~T}_{3}=0.1469$ & $\mathrm{~T}_{3}=0.3231$ \\
\hline PSS $_{3}$ & $\mathrm{~K}=5.2641$ & $\mathrm{~K}=4.7541$ & $\mathrm{~K}=7.8875$ \\
& $\mathrm{~T}_{1}=0.3234$ & $\mathrm{~T}_{1}=0.5361$ & $\mathrm{~T}_{1}=0.5668$ \\
& $\mathrm{~T}_{3}=0.1861$ & $\mathrm{~T}_{3}=0.3931$ & $\mathrm{~T}_{3}=0.4567$ \\
\hline
\end{tabular}

\subsection{RESPONSE FOR LIGHT LOAD EVENT}

The powerfulness of the adjudicated controller is evidenced by simulating a 3phase fault closed to bus 7 of 6 interval at 1 second. The system responses are conferred in Figures 3, 4, 5 for light load event. It is axiomatic that, the responses with the 
adjudicated GOAPSS are better than DEPSS and PSOPSS. Also, times of settling are 2.2, 3.5, and 3.2 second with GOAPSS, PSOPSS, and DEPSS respectively. The adjudicated controller is qualified to administer expedient damping property compared with PSOPSS and DEPSS.

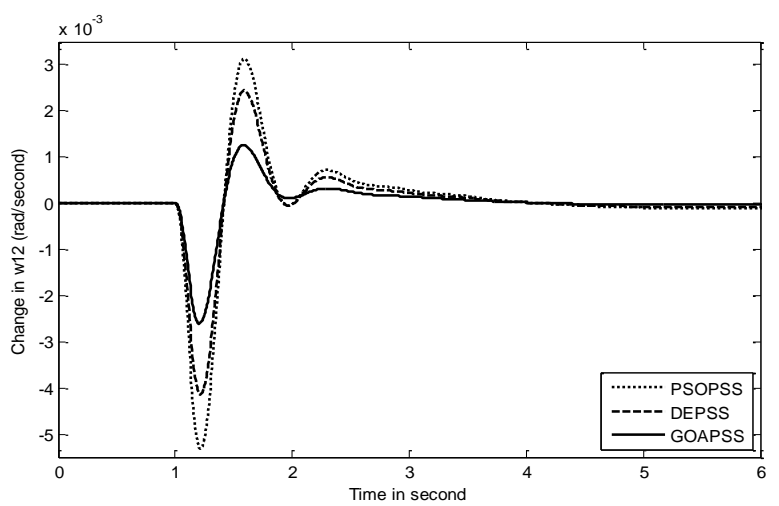

Fig. 3. Response of $\Delta \omega_{12}$ for light load event.

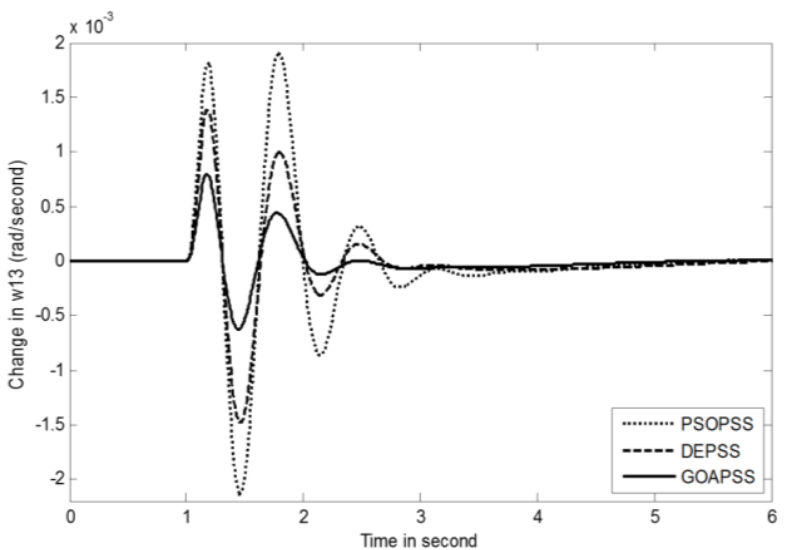

Fig. 4. Response of $\Delta \omega_{13}$ for light load event.

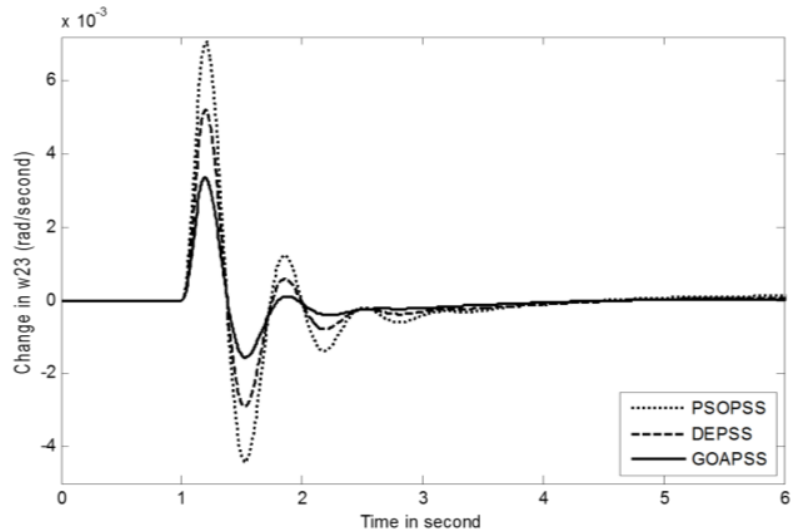

Fig. 5. Response of $\Delta \omega_{23}$ for light load event

\subsection{RESPONSE FOR NATURAL LOAD EVENT}

The system responses under natural load event are granted in Figures 6, 7, 8. From these responses, the damping property has been ameliorated by the adjudicated GOAPSS. The settling times of these responses are $T_{S}=2.4,3.2$, and 3.1 second for GOAPSS, PSOPSS, and DEPSS respectively. Also, the adjudicated GOAPSS outlasts PSOPSS and DEPSS in shortening oscillations and reducing the time of settling. Hence, the adjudicated GOAPSS amplifies the system stability boundary.

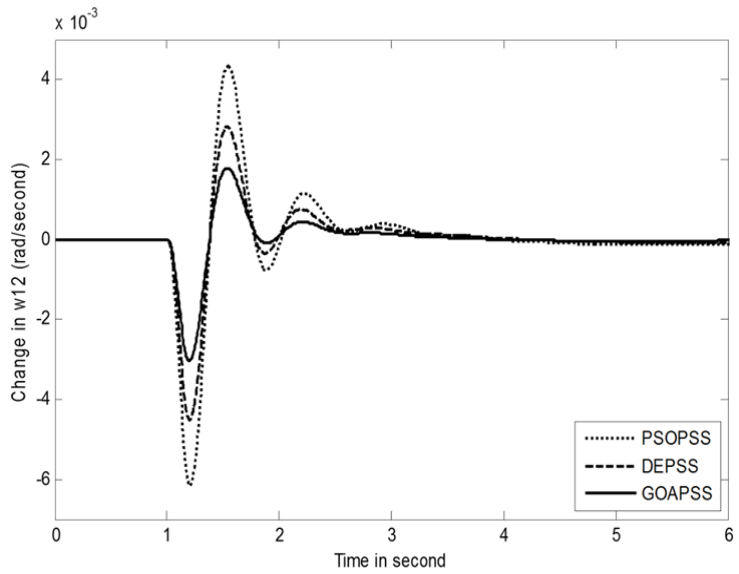

Fig. 6. Response of $\Delta \omega_{12}$ for natural load event.

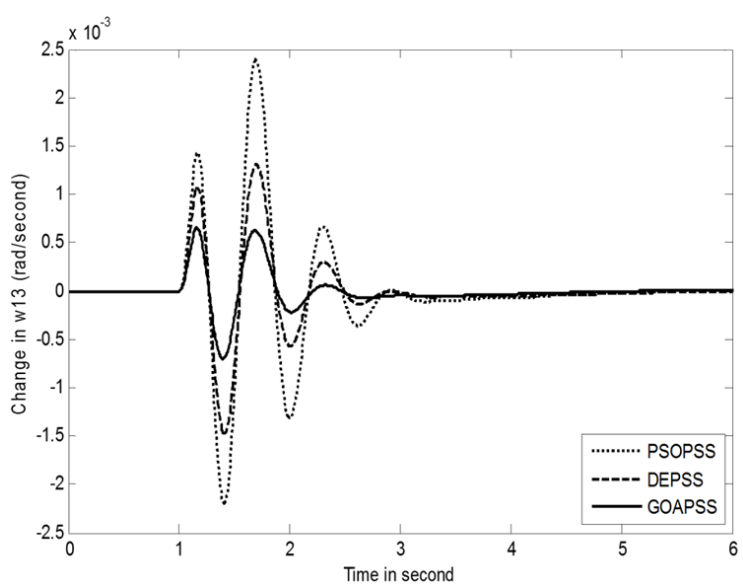

Fig. 7. Response of $\Delta \omega_{13}$ for natural load event. 


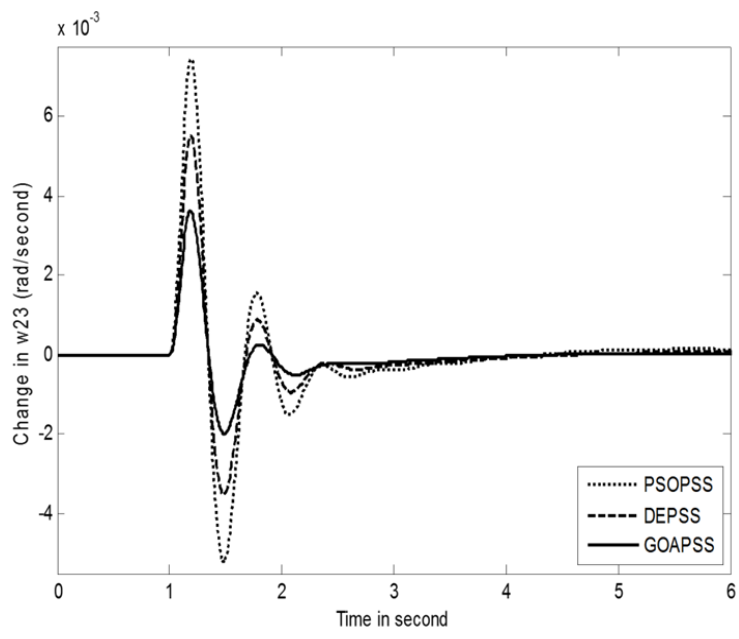

Fig. 8. Response of $\Delta \omega_{23}$ for natural load event.

\subsection{RESPONSE FOR HEAVY LOAD EVENT}

Figures 9, 10, 11 employ the responses for heavy load event. The powerfulness of the GOAPSS in faded system oscillations and denigrating the settling time are pointed in these figures. Also, times of settling of these oscillations are $T_{S}=2.5,3.3$, and 3.1 second for GOATPSS, PSOPSS, and DEPSS respectively. Thus, GOAPSS controller mostly develops the stability of system and evolves the damping property of power system. Moreover, the settling times of the adjudicated GOAPSS are smaller than these in $[5,12,19]$.

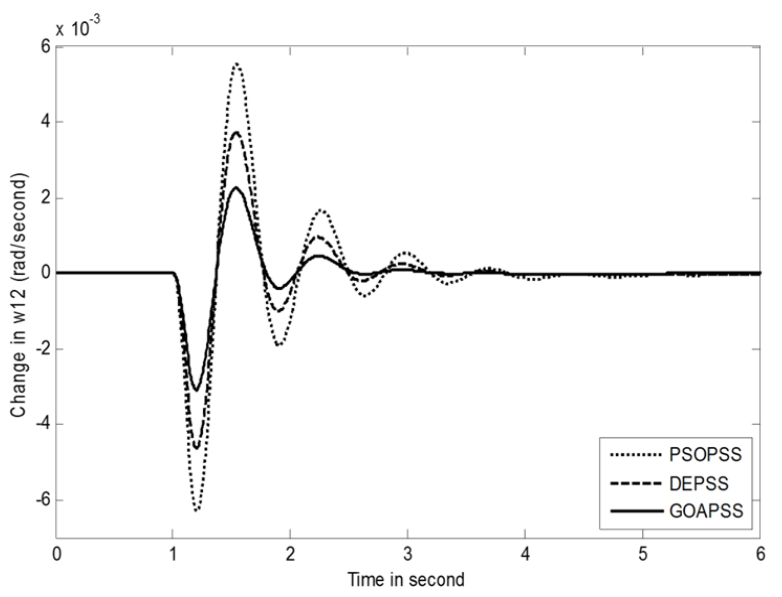

Fig. 9. Response of $\Delta \omega_{12}$ for heavy load event.

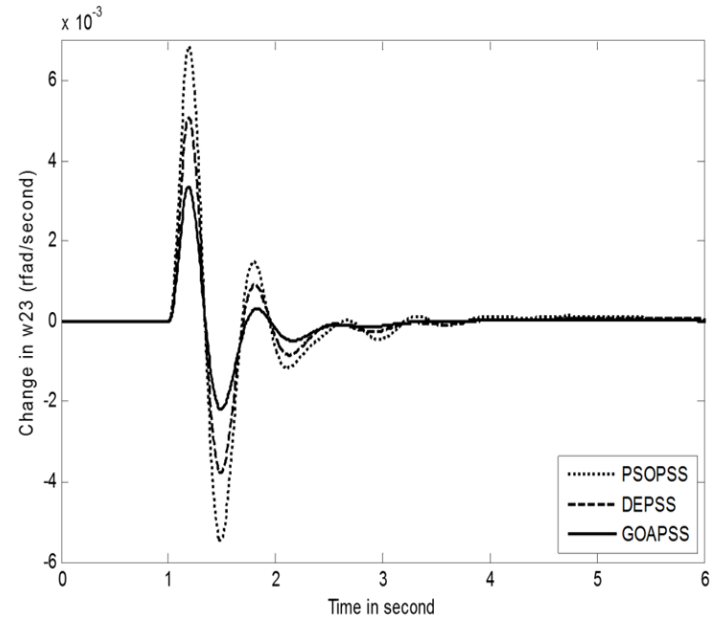

Fig. 10. Response of $\Delta \omega_{23}$ for heavy load event.

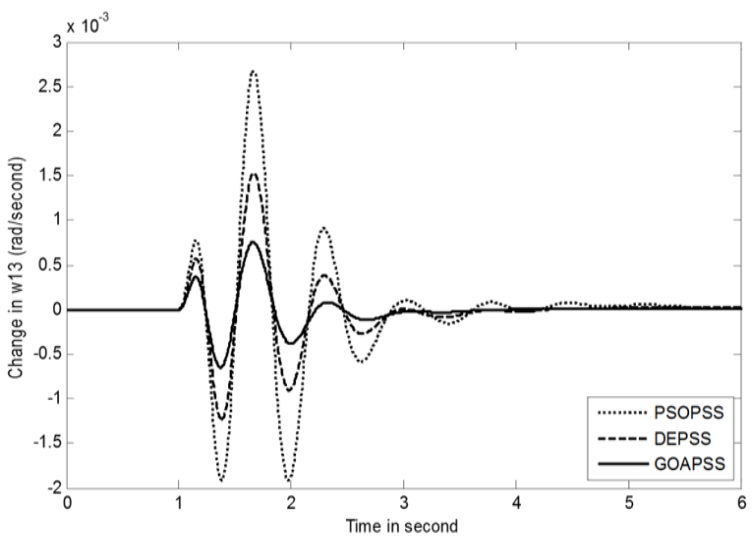

Fig. 11. Response of $\Delta \omega_{13}$ for heavy load event.

\subsection{RESPONSE UNDER SMALL DISTURBANCE}

The responses of $\Delta \omega_{13}$, and $\Delta \omega_{23}$ are donated in Figures 12, 13 due to 0.20 step increment in mechanical torque of machine 1 as a miniscule disturbance. It is distinct from these figures, GOAPSS constitutes dominant damping and evolve the best action compared with PSOPSS and DEPSS.

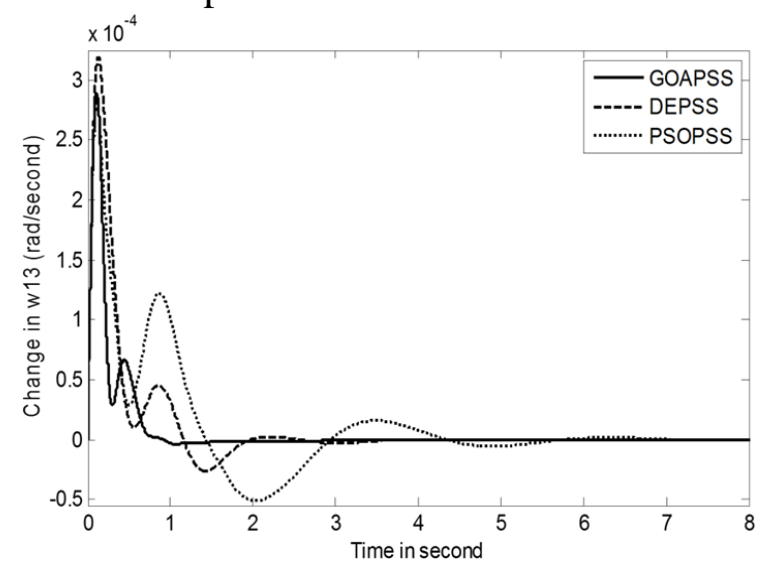

Fig. 12. Response of $\Delta \omega_{13}$ for miniscule disturbance. 


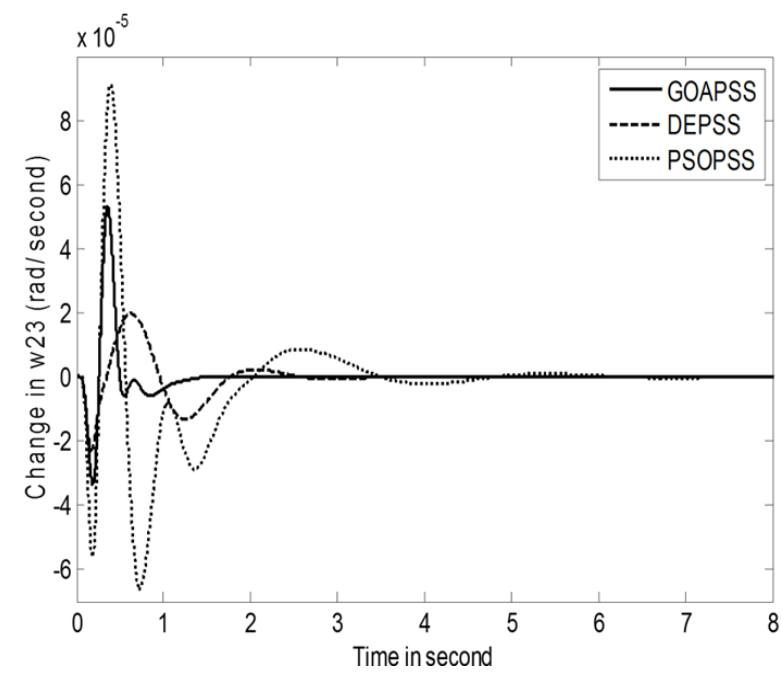

Fig. 13. Response of $\Delta \omega_{23}$ for miniscule disturbance.

\subsection{PERFORMANCE INDICES}

To judge the powerfulness of the adjudicated GOAPSS, two performance indices: the Integral of Absolute value of the Error (IAE), and ITAE are donated as:

$$
\begin{aligned}
& I A E=\int_{0}^{20}\left(\left|\Delta w_{12}\right|+\left|\Delta w_{23}\right|+\left|\Delta w_{13}\right|\right) d t \\
& I T A E=\int_{0}^{20} t\left(\left|\Delta w_{12}\right|+\left|\Delta w_{23}\right|+\left|\Delta w_{13}\right|\right) d t
\end{aligned}
$$

The more anemic the value of indices have, the more dominant the system response is. Numeral results of these indices for diverse events are granted in Table (3). It is distinct, that the quantities of these indices with the adjudicated GOAPSS are inferior compared with those of PSOPSS and DEPSS. This acquiesces that the speed deflections of all generators, overshoot, and settling time are extremely vitiated by setting the adjudicated GOA based orientated PSSs.

TABLE 3: PERFORMANCE INDICES FOR VARIED APPROACHES.

\begin{tabular}{|c|r|c|c|c|c|c|}
\hline & \multicolumn{3}{|c|}{ IAE * $10^{-4}$} & \multicolumn{3}{c|}{ ITAE * $10^{-4}$} \\
\cline { 2 - 7 } & PSOPSS & DEPSS & GOAPSS & PSOPSS & DEPSS & GOAPSS \\
\hline $\begin{array}{c}\text { Light } \\
\text { event }\end{array}$ & 0.2663 & 0.1484 & 0.0451 & 0.4642 & 0.4148 & 0.2746 \\
\hline $\begin{array}{c}\text { Natural } \\
\text { event }\end{array}$ & 0.3973 & 0.2648 & 0.0657 & 0.7756 & 0.7551 & 0.6001 \\
\hline $\begin{array}{c}\text { Heavy } \\
\text { event }\end{array}$ & 0.5686 & 0.4126 & 0.1001 & 0.9729 & 0.9406 & 0.8407 \\
\hline
\end{tabular}

\section{CONCLUSION}

In this paper, GOA is innovated for optimal tuning of PSSs parameters as denigrating the planned time orbit objective function. An ITAE of the generator speed is advised as the objective function to heighten the system stability. Simulation results inform the powerfulness of the adjudicated GOAPSS in giving good damping action to system oscillations for varied loading events. Also, the adjudicated GOAPSS declares it's effectively than DEPSS and PSOPSS through some indices. Coordination of FACT and PSS controller with GOA is the incoming scope of this paper.

\section{REFERENCES}

[1] P. Kundur, "Power System Stability and Control", McGraw-Hill, 1994.

[2] P. M. Anderson and A. A. Fouad, "Power System Control and Stability", Wiley- IEEE Press, 2nd edition, 2002.

[3] X. Yang, "Engineering Optimization: An Introduction with Metaheuristics Applications", Wiley, 2010.

[4] Z. Wang, C. Y. Chung, K. P. Wong, and C. T. Tse, "Robust Power System Stabilizer Design under Multi-Operating Conditions Using Differential Evolution", IET Generation, Transmission \& Distribution, Vol. 2, No. 5 , 2008, pp. 690-700.

[5] H. Shayeghi, H. A. Shayanfar, A. Safari, and R. Aghmasheh, "A Robust PSSs Design Using PSO in a Multimachine Environment", Int. J. of Energy Conversion and Management, Vol. 51, No. 4, 2010, pp. 696-702.

[6] E. S. Ali, and S. M. Abd-Elazim, "Coordinated Design of PSSs and TCSC via Bacterial Swarm Optimization Algorithm in a Multimachine Power System", Int. J. of Electrical Power and Energy Systems, Vol. 36, No. 1, March 2012, pp. 84-92.

[7] S. M. Abd-Elazim, and E. S. Ali, "A Hybrid Particle Swarm Optimization and Bacterial Foraging for Optimal Power System Stabilizers Design", Int. J. of Electrical Power and Energy Systems, Vol. 46, No. 1, March 2013, pp. 334341. 
[8] K. A. Hameed, and S. Palani, "Robust Design of Power System Stabilizer Using Harmony Search Algorithm", ATKAFF, Vol. 55, No. 2, 2014, pp. 162-169.

[9] D. Chitara, K. R. Niazi, A. Swarnkar, and N. Gupta, "Multimachine Power System Stabilizer Tuning Using Harmony Search Algorithm", 2016 Int. Conf. on Electrical Power and Energy Systems (ICEPES), 14-16 Dec. 2016.

[10] E. S. Ali, and S. M. Abd-Elazim, "Coordinated Design of PSSs and SVC via Bacteria Foraging Optimization Algorithm in a Multimachine Power System", Int. J. of Electrical Power and Energy Systems, Vol. 41, No. 1, Oct. 2012, pp. 44-53.

[11] E. S. Ali, and S. M. Abd-Elazim, "Power System Stability Enhancement via Bacteria Foraging Optimization Algorithm", Int. Arabian Journal for Science and Engineering, Vol. 38, No. 3, March 2013, pp. 599-611.

[12] E. Ali, "Optimization of Power System Stabilizers Using BAT Search Algorithm”, Int. J. of Electrical Power and Energy Systems, Vol. 61, No. C, Oct. 2014, pp. 386-690.

[13] D. K. Sambariya, R. Gupta, and R. Prasad, "Design of Optimal Input-Output Scaling Factors based Fuzzy PSS Using Bat Algorithm", Engineering Science and Technology, an Int. J., Vol. 19, Issue 2, June 2016, pp. 991-1002.

[14] N. Ghaffarzadeh, "Water Cycle Algorithm Based Power System Stabilizer Robust Design for Power Systems", J. of Electrical Engineering, Vol. 66, No. 2, 2015, pp. 91- 96.

[15] M. Shafiullah, M. A. Abido, and L. S. Coelho, "Design of Robust PSS in Multimachine Power Systems Using Backtracking Search Algorithm", In Proceedings of the 18th Int. Conf. on Intelligent System Application to Power Systems (ISAP), Sep. 2015, pp.1-6.

[16] N. Niamul Islam, M. A. Hannan, A. Mohamed, and H. Shareef, "Improved Power System Stability Using Backtracking Search Algorithm for Coordination Design of PSS and TCSC Damping Controller", PLOS ONE, Vol. 11, No.1, January 2016, pp. e0146277.

[17] M. R. Shakarami, I. F. Davoudkhani, "WideArea Power System Stabilizer Design based on Grey Wolf Optimization Algorithm Considering The Time Delay", Electric Power Systems Research, Vol. 133, April 2016, pp. 149-159.
[18] N. A. M. Kamari, I. Musirin, Z. Othman, and S. A. Halim "PSS Based Angle Stability Improvement Using Whale Optimization Approach", Indonesian J. of Electrical Engineering and Computer Science, Vol. 8, No. 2, Nov. 2017, pp. $382-390$.

[19] S. M. Abd-Elazim, and E. S. Ali, "Optimal Power System Stabilizers Design via Cuckoo Search Algorithm", Int. J. of Electrical Power and Energy Systems, Vol. 75 C, Feb. 2016, pp. 99-107.

[20] D. Chitara, K. R. Niazi. A. Swarnkar, and N. Gupta, "Cuckoo Search Optimization Algorithm for Designing of a Multimachine Power System Stabilizer", IEEE Transactions on Industry Applications, Vol. 54, No. 4, 2018 , pp. 3056 - 3065 .

[21] S. Venkateswarlu1, M. Janaki, and R. Thirumalaivasan, "Design of Power System Stabilizer Using Flower Pollination Algorithm", Int. J. of Engineering \& Technology, 7 (4.10), 2018, pp.177-181.

[22] M. Shafiullah, M. J. Rana, M. S. Alam, and M. A. Abido, "Online Tuning of Power System Stabilizer Employing Genetic Programming for Stability Enhancement", J. of Electrical Systems and Information Technology, Vol. 5, 2018, pp. 287-299.

[23] S. Ekinci, A. Demiroren, and B. Hekimoglu, "Parameter Optimization of Power System Stabilizers via Kidney-Inspired Algorithm", Trans. Inst. Meas. Control, Vol. 41, No. 5, 2019, pp. 1405-1417.

[24] S. Saremi, S. Mirjalili, and A. Lewis, "Grasshopper Optimization Algorithm: Theory and Application", Advances in Engineering Software, Vol. 105, 2017, pp.30-47.

[25] S. M. Abd-Elazim, and E. S. Ali, "Optimal SSSC Design for Damping Power Systems Oscillations via Gravitational Search Algorithm", Int. J. of Electrical Power and Energy Systems, Vol. 82 C, Nov. 2016, pp. 161-168.

[26] X. Wenhan, W. Yuanxing, Q. Di and B. D. Rouyendegh, "Improved Grasshopper Optimization Algorithm to Solve Energy Consuming Reduction of Chiller Loading", Energy Sources, Part A: Recovery, Utilization, and Environmental Effects, DOI: 10.1080/15567036.2019.1687622. 
[27] S. Arora, and P. Anand, "Chaotic Grasshopper Optimization Algorithm for Global optimization", Neural Computing and Applications, 2019, Vol. 31, No. 8, pp. 43854405, https://doi.org/10.1007/s00521-0183343-2.

[28] H. Jia ,C. Lang, D. Oliva, W. Song and X. Peng, "Hybrid Grasshopper Optimization Algorithm and Differential Evolution for Multilevel Satellite Image Segmentation", Remote Sens. , Vol. 11, 2019, pp. 1134.
[29] H. Hichem, M. Elkamel, M. R., M. T. Mesaaoud, C. Ouahiba, "A New Binary Grasshopper Optimization Algorithm for Feature Selection Problem", Journal of King Saud University - Computer and Information Sciences,

https://www.sciencedirect.com/science/article/p ii/S1319157819308900?via\%3Dihub. 